\title{
The Initial Exploration to Language Attrition and Memory Features for Students in Primary School
}

\author{
Yuhuan Zhang ${ }^{1, a^{*}}$ \\ ${ }^{1}$ School of Foreign Languages, China West Normal University, China, No. 1 Shi Da Road, \\ Shunqing District, Nanchong, 637009, Sichuan, China \\ ajuliezhyh@163.com
}

Keywords: Language attrition; Memory features; Students in primary school

\begin{abstract}
Here is the plain truth: students starting English study are becoming younger and younger and starting English as a student in Grade Three in primary school is compulsory according to official document. It is proved that people's language proficiency in their childhood starting a foreign language study is not better than that in their puberty staring a foreign language study, so how to make the students starting to learn a foreign language prioritizes to others is English teachers in primary school care most. The teachers are inclined to help students develop an interest of English, enhance their language tense and focus on pronunciation according to students' memory features in order to stop language attrition from dampening the students' enthusiasm of learning English.
\end{abstract}

\section{Introduction}

Since the reform and opening up, foreign language education in China has obtained the swift and rapid growth and the scale and quality has improved significantly and remarkably. The future of English language as a world language is increasingly bright. More and more Chinese people choose to learn English as a foreign language. The Chinese Ministry of Education also issued a decision that, from the autumn of the year 2001, all primary schools in both cities and towns need to offer an English course [1]. According to the official document, it means that starting English as a child is compulsory. Meanwhile, training institutions always preach that they can make students get high marks in a short time or they have some secrets of success to improve English or speak English fluently. In addition, if people want to get promotion or attend entrance examination, they have to take part in the related English exams. Even some children have to learn English in some learning institutions although they are just kindergarten children. But it is heard that students make complaints about their low language proficiency after more than ten years of learning English, how to learn English well or returning English to English teachers.... As a matter of fact, what has brought about such reluctance but a reality is language attrition. Moreover, it is common to meet such a strange phenomenon_-English teaching in China focusing on cultivation of English skills and abilities but maintainance of English language proficiency in the condition of lacking target language environment. Compared with language acquisition, materials about language attrition is not abundant. This paper, established in the reality of English learning in primary school, is to interpret the implication of the maintainance of English skills and proficiency from language attrition and students' memory principles; thus it makes English teachers take how to maintain students' language proficiency into account when they teach English.

\section{Related Definition and Researches}

Language attrition describes the loss of, or changes to, grammatical and other features of a language as a result of declining use by speakers who have changed their linguistic environment and language habits. In such a situation there may, for example, be simplification in the tense system or in certain properties of subordinate clauses; some vocabulary items might fall into disuse and phonetic features may be restructured. These changes can be affected by factors in the speaker' s environment and also by his or her attitudes, and processes of identification. [2] To some degree, language attrition is a decaying or stagnation phenomenon of language knowledge or language skills because of lack of use 
after learners experience foreign language or second language teaching. It is obvious that language attrition is not a mutability of language loss but gradualness. How to prevent language attrition take place in the process of English learning is worthy of consideration in Foreign Language Teaching. According to the attrition of different languages, e.g. the first language (L1) or the second language (L2), and the different environments where attrition happens, e.g. in an L1 environment or an L2 environment (Table 1), language attrition falls into four sorts. (Table 1)

Table 1

\begin{tabular}{|l|l|}
\hline L1 in a L1 environment (Type 1) & L1 in a L2 environment (Type 2) \\
\hline L2 in a L1 environment (Type 3) & L2 in a L2 environment (Type 4) \\
\hline
\end{tabular}

(Based on van Els[3] )

What English teachers in China have to face is foreign language attrition $-\mathrm{L} 2$ in a L1 environment (Type 3) in the situation of lacking register. The official document from Ministry of Education has advocated that students in Grade Three in Primary School regardless of in rural or urban have to begin learning English. Students in Grade Three usually are at age of eight or nine years; therefore, such students fall into the group of operational stage from seven to eleven years according to Piaget's theory on cognitive development.

Language attrition in the early 1980s has attracted the attention of foreign scholars. The landmark is Conference on the attrition of language skills in University of Pennsylvania. Since then, researchers in foreign countries have begun to do study on language attrition in its full swing. Compared with the researches in foreign languages, materials about language attrition are so limited. Until 2000s, researchers in China have started to focus on language attrition, most of who just introduced the language attrition studied in foreign countries, listed the factors related with language attrition or mainly displayed the implication in foreign language teaching in China. In our country, English learning has the features of high input and low output, so researches on preventing language attrition from happening are helpful for language learning and Foreign Language Teaching.

\section{The Relationship between Language Attrition and Memory Principles}

What is to influence language acquisition is also to influence language attrition. Köpke and S. Schmid [4] got the point that frequency, amount and settings of use of the attriting language play an important role in previous studies. In other words, language contact and students' own features of memory principles have a great effect on language efficiency and the level of language attrition. Memory is the reflection of past experience in the brain, including memorization, maintainance, recognition and reproduction — the four basic processes [5]. According the length of memory maintainance, memory can be divided into three kinds: instantaneous memory, short-term memory and long-term memory [6]. Instantaneous memory refers to raw material; the storage of short-term memory is so limited and it is ephemeral; long-term memory, to some degree, can keep the information as lifelong memory and the storage and space can be understood as boundless. Therefore, when instantaneous and short-term memories are transferred into long-term memory by ways of information input and encoding, information can be maintained in the brain for a long time and it is not easy that language attrition takes place. But forgetting, to some degree, can be called as a kind of language attrition. It refers to that people have no ability of recognition and reproduction or people make mistakes in the process of recognition and reproduction. As a result, people should notice the external stimulus, process them and transform them into short-term memory. After reviewing in time, such short-term memory can form long-term memory and people can recognize and reproduce the materials completely during the stage of information extraction. Reviewing in fits and starts is not a good way to hold back language attrition. As a matter of fact, the critical period of language attrition is incubation time [7] of language knowledge, the stage between the time of foreign language courses ending and the time of foreign language aptitude test. It is also the critical period of the retainment of language knowledge and skills or the most vulnerable period of memory; hence it is necessary to grasp and find chances to use the foreign language and review what have been learned with hopes of disturbing language attrition. 


\section{The Features of Students in Grade Three in Primary School}

It is required that students in Grade Three in Primary School in China have to begin to study English. Although nowadays many English experts disagree that children begin to learn English, it still exists a English fever— more and more Chinese people are crazy about English study and people who begin to learn English are becoming younger and younger. How to help such little Chinese students cultivate their interest of learning English and prevent them from language attrition of English is obviously significant for English teachers in Primary Schools, so it is necessary for the teachers to know well about the features of students' memory. To some degree, a good memory is a requisite condition of getting high scores. Students, who have impossibility to experience predecessors' great civilization, have to master their accumulated scientific and cultural knowledge in a short time. If they have a bad memory, they cannot make it. One typical characteristic of their memory is intentional memory increasing and unintentional memory decreasing, because students have to remember more materials relating with their learning contents, with their increasing academic pressure and study tasks. When students enter primary schools, their study must make their memory obedient to their learning without ever interest [8]. It is acknowledged that it is impossible for students to be interested in each subject or each topic or any content. What they can do is to learn the contents with consciousness. Different learning tasks can give training to their memories. English teachers attempt to build a perfect and harmonious environment for students to learning English. They try to make their English lessons lively and interesting to attract the students. Although the students' intentional memory increasing, teaching can make students produce their unintentional memory if teaching arouses their keen interest. English drills cannot separate from students' intentional memory; while simple and funny English jokes and story can promote their unintentional memory to remember English words, collocations and expressions in an easy way. Unintentional memory can improve learning effects. If students have a great interest in English, they are willing to spend more on English study and it is much easier for them to achieve a high level of language efficiency. Hence, it is difficult for language attrition to take place. For preschool children, they incline to rote memory; while for students in primary schools, and they have a tendency to recite materials on the basis of their understanding. In other words, meaningful and comprehensive memory prioritizes to rote memory. Reciting, based on comprehension, is a significant memory method. The more thoroughly students understand, the more easily they remember. Comprehension can help students to master contents better and easier, which can hold back their language attrition.

\section{Implication in Foreign Language Teaching}

Making a general survey of Chinese people's enthusiasm of learning English, this is closely linked with their entrance examinations, promotion and title performance evaluation, etc. But for students in Grade Three in primary school, English teachers should combine English its own features with students' memory features to guide students to achieve language efficiency. Comprehension can help students to remember what have been learned and store such information in their brains. Teachers had better explain the contents more thoroughly and more clearly, which can help students easy to understand and remember. Teachers guide students to review what they have learned about English before. According to forgetting curve, forgetting is more at the beginning than that later. Even if the materials have just been learned, people may forget them in a short time. As a result, it is necessary to promote the effects of reviewing. What is the best way is to review before forgetting takes place. Teachers, to some extent, can remind students of reviewing on time even if they achieve a certain degree of language efficiency. In that condition, it is not easy to language attrition to take place. For every person, perhaps it is not possible to store all the information in a certain stage of time. Overinformativeness really exists in people's life, so students can disperse what they need to review in different stages of time, among which intervals are not long. In that case, students spend less time to review a certain quantity of material each time, which will not cause to their disgusting. On the contrary, students spend less time in getting high language efficiency. In addition, every day they increase time on language contact, which is much better than that students spend one day in studying English after a long time of no English contact. They can 
increase their consciousness of learning English often; it is natural that language attrition can happen hardly.

\section{Conclusion}

Throughout the foreign language education in China, great changes have taken place in foreign language teaching and foreign language education has made great progress. Children who start to learn English become younger and younger; the number of learning English is becoming bigger and bigger. In addition, many people are always making complaints about forgetting English and having English dissiliency. There exist some people around the writer who began to learn English in kindergarten, but their English proficiency has not priority to that of peers, so how to make such people starting English study in their childhood have their own advantage of learning English when they become adults is worthy of consideration. What is English teachers care most in primary school is to help students develop an interest of English, enhance their language tense and focus on pronunciation. Moreover, based on students' memory features, it is necessary for English teachers to organize students to review what they have learned about English in different time and in different stages of memory with different methods in order to consolidate their English knowledge and skills, preventing their language attrition from happening.

\section{References}

[1] Ministry of Education. (2001). English Curriculum Requirement in Elementary and Secondary Schools

[2] Monika S.Schmid Language attrition Cambridge: Cambridge Press 2011

[3] Van Els, T. (1986). An Overview of European Research on Language Attrition. Language Attrition in Progress. The Netherlands Foris Publication.

[4] Barbara Köpke\&Monika S.Schmid. (2002). Language attrition First Language Attrition: Interdisciplinary perspectives on methodological issues Amsterdam: John Benjamins Publishing Co.

[5] Gong Weiyi\& Liu Xinmin. (2004).Developmental psychology. Beijing: Beijing Science and Technology Press.

[6] Wang Naiming\& Qian Feng. (2006). Preschool Psychology. Shanghai: Fudan University Press.

[7] Li Ping\& Zheng Shutang (2004). Language loss and retainment. Shandong Foreign Language Teaching, (5).

[8] Wu Fenggang. (1981).students' memory characteristics and teaching in primary school. Quoted in Zhu Zhixian. Children's Education Psychology. Beijing: Beijing Normal University Press. 55-59 